\title{
A green \&natural method for removing of nitride from light oil by $\beta$-Cyclodextrin aqueous solution through molecular recognition*
}

\author{
Zun-Bin Duan, Lin-Lin Li, Ting-Ting Bu, Li-Jun Zhu and Dao-Hong $\mathrm{Xia}^{\dagger}$ \\ State Key Laboratory of Heavy Oil Processing, \\ China University of Petroleum (East China), \\ Qingdao 266580, PR China \\ tE-mail:xiadh@upc.edu.cn
}

\begin{abstract}
$\beta$-Cyclodextrin ( $\beta$-CD) aqueous solution was firstly used into the removal of nitride from light oil by molecular recognition. Pyridine was chosen as a model compound and used in the denitrification experiments. And the influence factors, concentration of $\beta-\mathrm{CD}$, time, ratio of catalyst to oil and temperature were investigated. And the optimum denitrification conditions were as well obtained. Besides, we used UV-vis absorption spectra to study the inclusion process. It was found that inclusion ratio of inclusion complex between $\beta$ CD and pyridine was $1: 1$. Possible denitrification mechanism models were proposed. This work lays the foundation of denitrification by molecular recognition with $\beta$-CD.

Keywords: $\beta$-Cyclodextrin; Pyridine; Denitrification; Molecular recognition; Inclusion Complexation.
\end{abstract}

\section{Introduction}

Recently, with the increasing enhancement of environmental protection and development of automobile industry, people have a growing demand on the cleanliness of light oil. However, nitrogen compounds contained in the fuel greatly affect the quality of oil and the environmental protection. Hydrogenation gentrification technology is mature and widely used, but has a large consumption of hydrogen and equipment investment, which causes saturation of olefin and reduce its octane number. There out, no hydrogenation gentrification technology has been developed. But, truly effective gentrification technology does not been found, and needs to be urgently exploited. $\beta$-Cyclodextrin ( $\beta$-CD) has a useful application in separation of drug by molecular recognition, but does not been used into the gentrification of light oil [1].

\footnotetext{
* The authors thank the National Natural Science Foundation of China (Grant No. 21376265) and China University of Petroleum for Postgraduate Technology Innovation Project (Grant No.YCX2015023) for financial support.
} 
$\beta-\mathrm{CD}$, containing peculiar hydrophobic cavum, could form inclusion complexes with various organic/biological molecules by molecular recognition [2]. Krishnan Srinivasan et al [3-5] studied the inclusion complex of $\beta$ cyclodextrin with 2,6-dinitrobenzoic acid, 2,4-dinitroaniline and 2,6dinitroaniline by different analytical methods, and reported that they formed 1:1 inclusion complex with $\beta$-CD. Sun et al [6] researched the inclusion of 1propanethiol in light oil by $\beta-\mathrm{CD}$ and firstly realized the removal of sulfur compound from light oil by $\beta$-CD. However, the inclusion interaction between $\beta-\mathrm{CD}$ and pyridine (Py) has not been reported.

In this study, the inclusion interaction of $\beta-C D$ with Py was investigated by UV-vis absorption spectra. And Py in light oil was effectively removed by molecular recognition with $\beta-C D$. Possible denitrification mechanism models were proposed in the end.

\section{Experimental}

\subsection{Materials and instruments}

All chemical reagents were A.R. grade. $\beta$-CD was recrystallized for three times before use. And pyridine was distilled before use.

UV-vis absorption spectra were determined on a Hitachi U-3900H UV-Vis spectrophotometer at different temperatures. The nitrogen content in the simulated oil was measured by a ANTEK9000 NS analyzer.

\section{2. $U V$-vis absorption spectra}

The inclusion complexation of $\beta-\mathrm{CD}$ with $\mathrm{Py}$ was researched by the direct optical spectrographic method in phosphate buffer solution $(\mathrm{pH}=6.86)$ at different temperatures. The buffer solution of pyridine and pyridine with different concentration of $\beta-\mathrm{CD}$ was firstly stored for $50 \mathrm{~min}$ at $25^{\circ} \mathrm{C}$. And then $\mathrm{UV}$-vis absorption spectra of different solutions were analyzed at the same temperature. Meanwhile, UV-vis absorption spectra at $30^{\circ} \mathrm{C}, 35^{\circ} \mathrm{C}, 40^{\circ} \mathrm{C}$ and 50 ${ }^{\circ} \mathrm{C}$ were measured at the same condition. The initial concentration of pyridine in phosphate buffer solution was $1.242 \times 10^{-3} \mathrm{~mol} \cdot \mathrm{L}^{-1}$, and the initial concentration of $\beta$-CD was in the range of $8.000 \times 10^{-4} \mathrm{~mol} \cdot \mathrm{L}^{-1} \sim 8.000 \times 10^{-3} \mathrm{~mol} \cdot \mathrm{L}^{-1}$.

\subsection{Denitrification experiments}

Py was dissolved into $n$-heptane (simulated oil), and the initial concentration was $100 \mu \mathrm{g} \cdot \mathrm{g}^{-1}$. Aqueous solution with different concentration of $\beta-C D$ was mixed with simulated oil under mechanical stirring at room temperature. And 
the nitrogen content was measured by a ANTEK 9000 NS analyzer and to calculate the nitrogen removal rate as the following Eq. (1).

$$
\text { Denitrification } \operatorname{rate}(\%)=\left[\left(\mathrm{C}_{0}-\mathrm{C}_{\mathrm{t}}\right) / \mathrm{C}_{0}\right] \times 100
$$

Where $\mathrm{C}_{0}$ is the initial concentration of nitrogen in the simulated oil, $\mathrm{C}_{\mathrm{t}}$ is the final concentration of nitrogen in the simulated oil.

\section{Results and Discussion}

\section{1. $U V$-vis absorption spectra}
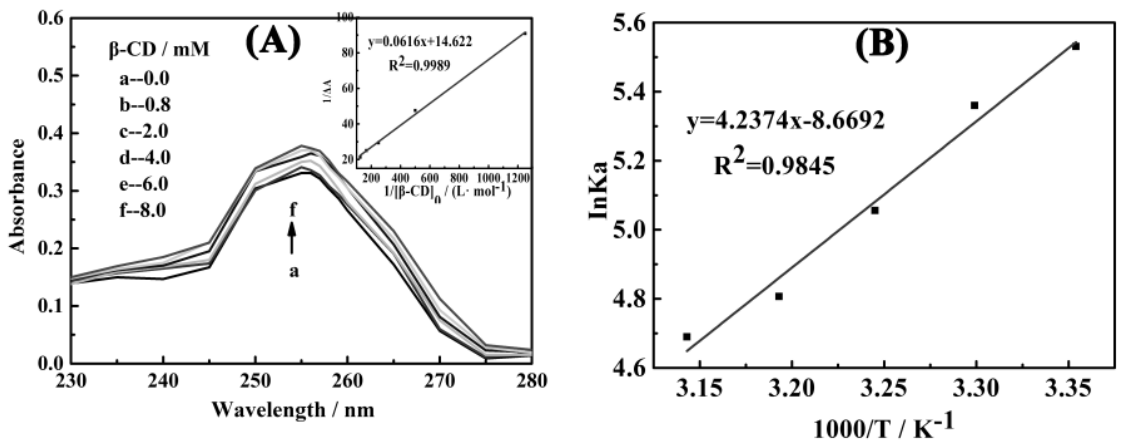

Fig. 1. (A) UV-vis absorption spectra of pyridine at $25.0^{\circ} \mathrm{C}$ with the increase of $\beta$-CD concentration in phosphate buffer solution( $\mathrm{pH}=6.86$ ) (insert: $\mathrm{B}-\mathrm{H} \mathrm{UV}$-vis absorption plot of Py with $\beta$-CD); (B) Plotting lnKa versus 1000/T for the inclusion complex of $\beta$-CD with pyridine

With the introduction of $\beta-\mathrm{CD}$, the maximum absorption of the system still appeared at 255nm (Figure 1(A)). Moreover, the absorbance gradually enhanced with the increase of $\beta-C D$, which implied the formation of inclusion compound of $\beta-C D$ with Py ( $\beta-C D$ :Py) [4]. The inside cavity of $\beta-C D$ is hydrophobic, and Py enter into the inside cavity of $\beta-C D$, which causes the change of absorption spectra changes of the system.

If inclusion ratio of $\beta-\mathrm{CD}: \mathrm{Py}$ is $1: 1$, and the inclusion reaction of $\beta-\mathrm{CD}$ with Py is as follows:

$$
\beta-\mathrm{CD}+\mathrm{Py} \stackrel{\mathrm{Ka}}{\Leftrightarrow} \beta-\mathrm{CD} \cdot \mathrm{Py}
$$

And the inclusion constant $(\mathrm{Ka})$ is given by

$$
\mathrm{Ka}=\frac{[\beta-\mathrm{CD} \cdot \mathrm{Py}]}{[\beta-\mathrm{CD}] \cdot[\mathrm{Py}]}
$$

The inclusion constant (Ka) can be obtained by using the $\mathrm{B}-\mathrm{H}$ equation [7] for the inclusion complex of 1:1 inclusion ratio (Eq. (4)). 


$$
\frac{1}{\Delta \mathrm{A}}=\frac{1}{\mathrm{Ka} \Delta \varepsilon_{\beta-\mathrm{CD} \cdot \mathrm{Py}}[\mathrm{Py}]_{0}} \times \frac{1}{[\beta-\mathrm{CD}]_{0}}+\frac{1}{\Delta \varepsilon_{\beta-\mathrm{CD} \cdot \mathrm{Py}}[\mathrm{Py}]_{0}}
$$

Where $\Delta \mathrm{A}$ is the difference between the absorbance of Py in the presence and absence of $\beta$-CD. $\Delta \varepsilon_{\beta-C D \cdot P y}$ is the difference between the molar absorption coefficient of Py and the inclusion complex. $[\beta-\mathrm{CD}]_{0}$ and $[\mathrm{Py}]_{0}$ are the initial concentration of $\beta-\mathrm{CD}$ and $\mathrm{Py}$.

Figure $1(\mathrm{~A})$ (insert) shows a plot of $1 / \Delta \mathrm{A}$ as a function of $1 /[\beta-\mathrm{CD}]_{0}$ for Py. A good linear correlation with $\mathrm{R}^{2}=0.9989$ confirmed the formation of $1: 1$ inclusion complex. Ka was obtained by the slope and intercept of the B-H plot by using Eq. (4), which was $252.35 \mathrm{~L} \cdot \mathrm{mol}^{-1}$. And Kaat different temperatures were listed in table 1 . The result shows that $\mathrm{Ka}$ decreased with the increasing temperature from $25{ }^{\circ} \mathrm{C}$ to $50{ }^{\circ} \mathrm{C}$. The higher temperature was a disadvantage factor for the inclusion process.

Table 1. The stability constant Ka of the inclusion of pyridine with $\beta$-CD at different temperatures

\begin{tabular}{cccccc}
\hline $\mathrm{T} /{ }^{\circ} \mathrm{C}$ & 25.0 & 30.0 & 35.0 & 40.0 & 50.0 \\
\hline $\mathrm{Ka} /\left(\mathrm{L} \cdot \mathrm{mol}^{-1}\right)$ & 252.35 & 212.77 & 156.91 & 122.41 & 85.08 \\
\hline
\end{tabular}

Thermodynamic parameters of the inclusion process, Gibbs free energy change $(\Delta \mathrm{G})$, enthalpy change $(\Delta \mathrm{H})$ and entropy change $(\Delta \mathrm{S})$ can be obtained from Eq. (5), (6) with Ka at different temperatures [8].

$$
\begin{aligned}
& \Delta \mathrm{G}=-\mathrm{RT} \ln \mathrm{Ka} \\
& \ln \mathrm{Ka}=-\frac{\Delta \mathrm{H}}{\mathrm{RT}}+\frac{\Delta \mathrm{S}}{\mathrm{R}}
\end{aligned}
$$

Where $\mathrm{R}$ is the universal gas constant and $\mathrm{T}$ is the absolute temperature. A good linear correlation between $\operatorname{lnKa}$ and $1000 / \mathrm{T}$ with $\mathrm{R}^{2}=0.9845$ was shown in Figure 1(B). $\Delta \mathrm{H}$ and $\Delta \mathrm{S}$ can be obtained from obtained by linear equation in Figure 2. The thermodynamic parameters were negative $\left(\Delta \mathrm{G}_{298.15 \mathrm{~K}}=-13.71\right.$ $\mathrm{kJ} \cdot \mathrm{mol}^{-1}, \Delta \mathrm{H}=-35.23 \mathrm{~kJ} \cdot \mathrm{mol}^{-1}, \Delta \mathrm{S}=-72.08 \mathrm{~J} \mathrm{~mol}^{-1} \cdot \mathrm{K}^{-1}$ ), which indicated that the inclusion processe was spontaneously endothermic and controlled by enthalpy. The negative $\Delta H$ values suggested that Van der Waals's force and electrostatic interactions were more important than hydrophobic interactions [9].

\subsection{Denitrification experiments}

We chose pyridine as model compound to study the possibility of denitrification process by $\beta-C D$ aqueous solution. The influence factors, time, mass concentration of $\beta-\mathrm{CD}$, ratio of catalyst to oil and temperature were shown in Figure 2. Py has certain solubility in aqueous solution, so the removal 
percentage of Py deducts the influence of the water. As seen from Figure 2(A), pyridine in simulated oil was indeed removed by $\beta-\mathrm{CD}$ aqueous solution. The optimum time of denitrification was $20 \mathrm{~min}$. After $20 \mathrm{~min}$, the removal percentage was gradually decreased. The removal percentage firstly increased and then decreased with the increase of mass concentration of $\beta-\mathrm{CD}$ in aqueous solution, and the optimum mass concentration of $\beta-\mathrm{CD}$ was $1.8 \mathrm{~m} \%$ (see in Figure 2(B)).

We also investigated the effect of ratio of catalyst to oil (Figure 2(C)). Although the $\beta-\mathrm{CD}$ content increased with the increasing ratio of catalyst to oil, the rate of Py removal increased and then decreased and the optimum ratio of catalyst to oil was 1:1. It means that the influence of the water on the removal of pyridine is predominant over that of $\beta$-CD through molecular recognition for denitrification when ratio of catalyst to oil was over $1: 1$.

Figure 2(D) was shown the result of effect of temperature on the removal of Py. With the increasing temperature form $25^{\circ} \mathrm{C}$ to $50^{\circ} \mathrm{C}$, removal percentage had a various degrees decrease. Temperature was an important factor on the removal of Py. Therefore, the denitrification process shall be carried out at room temperature. The result is consistent with research in UV-vis absorption spectra.
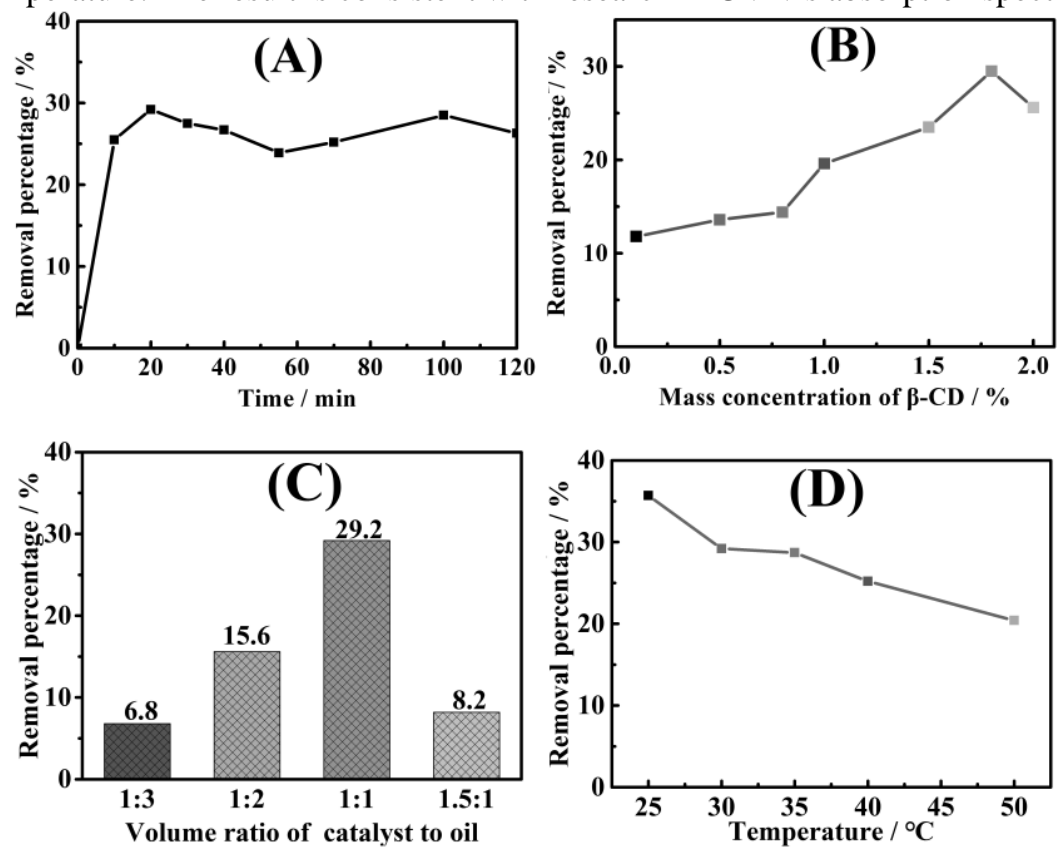

Fig. 2. Effect of (A) time (temperature, $30^{\circ} \mathrm{C}$; mass concentration of $\beta-\mathrm{CD}, 1.5 \mathrm{~m} \%$; volume ratio of catalyst to oil, 1:1), (B) mass concentration of $\beta$-CD (temperature, $30^{\circ} \mathrm{C}$; time, $20 \mathrm{~min}$; volume ratio of catalyst to oil, $1: 1$ ), (C) volume ratio of catalyst to oil (temperature, $30^{\circ} \mathrm{C}$; time, $20 \mathrm{~min}$; mass concentration of $\beta-\mathrm{CD}, 1.5 \mathrm{~m} \%$ ) and (D) temperature (time, $20 \mathrm{~min}$; mass concentration of $\beta-\mathrm{CD}$, $1.5 \mathrm{~m} \%$; volume ratio of catalyst to oil, $1: 1$ ) on the removal of pyridine by the $\beta$-CD aqueous solution 


\subsection{Mechanism of denitrification}

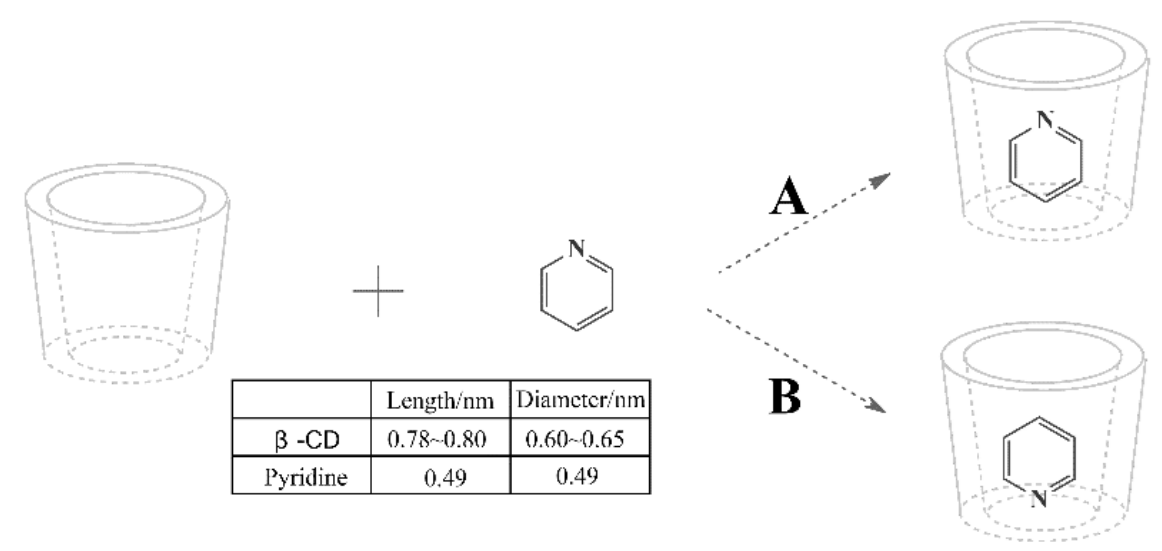

Fig. 3. Two possible denitrification mechanism models

The molecular size of Py is less than that of the cavity of $\beta-C D$. Therefore, $\beta-C D$ owning a hydrophobic cavity can recognize Py and they form 1:1 inclusion complex in aqueous solution, which realizes the removal of Py from light oil. According to the above results and molecular size of $\beta-C D$ and Py, two possible denitrification mechanism models were proposed (Figure 3). Two possible structure of inclusion complexes between $\beta-\mathrm{CD}$ and Py were reasonable, respectively.

\section{Conclusions}

The inclusion behaviour between $\beta-\mathrm{CD}$ and Py in phosphate buffer solutions at different temperatures was studied by UV-vis absorption spectra. It was found that Py could form 1:1 stoichiometry inclusion complex with $\beta-\mathrm{CD}$ and the inclusion process was spontaneously, endothermic and controlled by enthalpy. Moreover, a green \& natural method for removing of nitride from light oil by $\beta$ cyclodextrin aqueous solution through molecular recognition was proposed. And the optimum denitrification conditions were obtained. Two possible denitrification mechanism models were presented in the end. The research results will provide a totally new idea for denitrification and it is of great theoretical and practical significance.

\section{References}

1. K. Uekama, F. Hirayama, T. Irie, Chemical Reviews, 98(1998) 2045-2076.

2. Y. Chen, Y. Liu, Advanced Materials, 27(2015) 5403-5409.

3. S. Krishnan, S. Thambusamy, Molecular and Biomolecular Spectroscopy, 130(2014) 105-115. 
4. S.Thambusamy, S.Krishnan, S.Krishnamoorthy, Carbohydrate Polymers, 107(2014) 72-84.

5. S.Krishnan, S.Krishnamoorthy, S. Thambusamy, Carbohydrate Polymers, 113(2014) 577-587.

6. Y. Sun, D. Xia, Y. Xiang, Petroleum Science and Technology, 26(2008) 2023-2032.

7. A. Benesi, H. Hildebrand, Journal of the American Chemical Society, 71(1949) 2703-2707.

8. M. Liu, A. Chen, Y. Wang, C. Wang, B. Wang, D. Sun, Food Chemistry, 168(2015) 270-275.

9. N. Kalogeropoulos, S. Konteles, I. Mourtzinos, E. Troullidoua, A. Chioua, T. Karathanos, Journal of Microencapsulation, 26(2009) 603-613. 